\title{
A NOVA COBERTURA POLÍTICA MEDIADA POR ASSESSORIAS DE IMPRENSA EM CAMPANHAS ELEITORAIS
}

\author{
The new configuration of politics journalistic coverage established \\ by the mediation of Public Relations in election campaigns
}

\begin{abstract}
Flávia Clemente de Souza
Jornalista, graduada pela Universidade Federal Fluminense, com Mestrado em Comunicação, Imagem e Informação pela mesma instituição, é professora da Universidade Federal Fluminense, nas áreas de comunicação institucional e webjornalismo, Rio de Janeiro, RJ - Brasil, e-mail: flavia.clemente@gmail.com
\end{abstract}

\begin{abstract}
Resumo
A profissão de assessor de imprensa se configura como um verdadeiro enigma dentro do mercado de trabalho da comunicação social. Pouco compreendida, é cercada por polêmicas, dentre as quais o debate sobre a ética profissional dos que se dedicam a esta vertente do mercado. Partindo deste ponto de vista, as cores se tornam mais vivas quando vislumbrados os laços da assessoria de imprensa com a política. Profissionais formados em comunicação, em sua maioria jornalistas, adentraram este mundo para modificar o que se entendia, até então, por jornalismo político. Das redações para os cargos de confiança, tornaramse mediadores entre a figura dos candidatos e os repórteres, usando seus conhecimentos sobre os fenômenos comunicacionais para subverter a lógica tradicional da cobertura jornalística.
\end{abstract}

Palavras-chave: Assessoria de imprensa; Jornalismo político; Campanhas eleitorais.

\begin{abstract}
The Public Relations can be configured as the real puzzle of the relationship within the media. Not understood, they are surrounded by controversy, including the debate on the professional ethics of those who engage in this part of the profession. From this point of view, the colors become more vivid envisioned when we link Public Relations and Politics. Trained professionals in communication issues, mostly journalists, came into this world to change what was meant, until then, for political journalism. From the newspapers to strategic positions of trust, they have become mediators between the figure of candidates and the reporters, using their knowledge of the phenomena communication to subvert the logic of traditional journalistic coverage.
\end{abstract}

Keywords: Public relations; Political journalism; Election campaigns. 


\section{INTRODUÇÃO}

O discurso dos políticos no âmbito da esfera pública e, mais especificamente, sua reprodução filtrada pelo prisma do jornalismo - compreendendo nesta atividade tanto o que concerne ao trabalho nas redações quanto o das assessorias de imprensa - se apresenta como um campo de grande interesse para o estudo dos fenômenos da comunicação. Como vertentes mais recorrentes quando se busca analisar a relação entre o discurso político, a produção de notícias e a opinião pública, temos: (1) a tentativa de compreender de que forma se dá o fenômeno conhecido como agendamento; (2) a avaliação de como ocorrem as mediações consequentes da veiculação obrigatória do horário eleitoral gratuito na televisão, mídia que atinge a maior parcela do eleitorado e se mostra determinante para os resultados eleitorais.

No entanto, em ambos os casos, o que se analisa são os resultados na sociedade, consequentes do que já foi divulgado pelos veículos de comunicação. A partir dessa temática, nossa tentativa neste ensaio é nos deixarmos levar para um terreno ainda muito pouco explorado academicamente: o papel das assessorias de imprensa - especificamente dessa forma, responsável por seus resultados (sejam acertados ou não).

Apesar de ainda não se configurar como um meio de comunicação de massa - de acordo com Castells (2005, p. 262), "a média [de acesso à Internet] dos países ricos estaria, neste momento, em $25-30 \%$ [da população], enquanto na maioria do planeta está em menos de 3\%" -, a Internet mostrase como um dos recursos usados pelas assessorias de imprensa na mediação com as redações. Fato é que faz parte do repertório de qualquer jornalista, nos dias de hoje, a apuração "virtual". Há 30 anos, não se imaginaria uma redação sem máquinas de escrever e telefones, hoje não se imagina um repórter trabalhando sem acesso a um terminal conectado à Internet e a um endereço eletrônico. (Mas podemos imaginá-los redigindo três ou quatro notícias por dia sem precisar ir à rua nem entrevistar ninguém!). Os assessores de imprensa perceberam a importância do surgimento da Internet como nova tecnologia de apoio às redações e usam o meio para atingir justamente os jornalistas: público fundamental para a construção da imagem de seus candidatos.

Pode-se dizer que a Internet reconfigurou toda a engrenagem de produção de notícias políticas, estabelecendo relações diferenciadas entre jor- nalistas e fontes, criando um novo viés de funcionamento da apuração e, habitualmente, pautando as edições dos jornais impressos ou eletrônicos.

Como consequência, a produção de conteúdo das matérias políticas sofre clara influência das ações e estratégias formuladas pelos assessores de imprensa, que se valem, muitas vezes, do agendamento para alcançar seus objetivos. Hipótese que se comprova por meio da comparação entre o material produzido pelas assessorias de campanha e o que é publicado nos veículos.

\section{O caso particular da assessoria de imprensa no Brasil}

No Brasil, ao contrário da Europa e dos Estados Unidos, o assessor de imprensa se identifica profissionalmente com o jornalista. Mas por que os jornalistas se qualificam como os profissionais mais credenciados para exercer a função e, ao mesmo tempo, renegam a assessoria de imprensa como parte do mundo do jornalismo? Devemos levar em consideração que jornalistas em assessorias de imprensa são um caso típico brasileiro (CHAPARRO, 2003, p. 45). De acordo com Kopplin e Ferraretto (2001), "as AI, em meio à crise econômica dos anos 90, aparecem como o grande mercado de trabalho para jornalistas". Tanto nos Estados Unidos quanto na Europa, as assessorias são seara de Relações Públicas. Daí surge o segundo ponto a avaliar: por que os jornalistas assumiram as assessorias de imprensa no Brasil? Até a década de 60, mesmo em nosso país, esta tarefa era parte do trabalho de Relações Públicas (LIMA, 1985, p. 32). Nesse momento, vários fatores vieram a influenciar o mercado de trabalho e - em consonância com o crescimento da área - houve a migração de jornalistas das redações para as empresas e instituições.

Com o tempo, a profissão ganhou importância e, para alguns segmentos, passou a ser fundamental. No caso da política, quando os homens públicos em geral e os candidatos em particular perceberam a necessidade de contar com assessores de imprensa em seus quadros, um novo panorama passou a se formar nas mediações entre as redações e os políticos. Mais do que um simples cumpridor de tarefas, o assessor de imprensa passou a ser peça-chave em campanhas e ganhou participação no planejamento estratégico dos comitês eleitorais. 
Eleitoralmente, os candidatos são como que absorvidos ou "solicitados" por uma conjuntura político-social onde predomina uma esfera de valores midiática, suscetível de acionar a força plebiscitária das massas contra o formalismo burocrático, ou eventualmente doutrinário, dos partidos. A “absorção" implica, na prática, a conversão da identidade-político partidária do indivíduo em pura imagem pública, isto é, em aparência - constituída por um ou mais traços publicitariamente convenientes -experimentada como entidade original ou "virtualizada" (SODRÉ, 2006).

As campanhas eleitorais em si mudaram muito nas últimas duas décadas. A importância da mídia espontânea tornou-se acentuada, principalmente depois que todos os candidatos puderam contar com espaços formais na propaganda política gratuita e obrigatória transmitida pela têve. $\mathrm{O}$ surgimento da Internet foi um novo marco nas campanhas eleitorais, ampliando ainda mais o escopo de atuação dos políticos, em um espaço no qual a legislação ainda esbarra em muitas omissões, que permitem um uso político mais abrangente desta mídia, em função dos veículos tradicionais: tevê, rádio, jornais e revistas.

Também para as redações tudo mudou com o uso da Internet. O perfil profissional mudou: “o jornalista 'surfador' costuma ser jovem, frequenta os primeiros anos de um curso de jornalismo e foi contratado como estagiário" (FERRARI, 2004, p. 41). A apuração tornou-se mais rápida e simples, mas perdeu em precisão e independência. A facilidade do uso da tecnologia tem formado profissionais menos insistentes, que preferem escorar-se em releases e sites oficiais para produzir seus textos a correr atrás de matérias nas ruas. Isso tudo está refletido nas páginas impressas dos jornais, particularmente nos editorias de política. Enfim, cobrir campanhas ficou mais fácil, o conteúdo continua o mesmo? Como fica o jornalismo político diante dessa nova realidade?

E há ainda a intrincada questão da ética profissional jornalística, cujo código vigente - de três páginas somente - deixa muito a desejar, e a contradição inerente à condição de jornalistaassessor de imprensa, principalmente no campo da política. A questão é que todos admitem que o código de ética dos jornalistas não deve se aplicar à assessoria de imprensa. No entanto, não existe código para balizar este profissional, que só pode contar com o próprio bom-senso e as maleáveis fronteiras do que se entende por ética e moral no senso comum.

Abarcar todas as mudanças até aqui expostas poderia parecer, em um primeiro momento, procurar uma hipótese simplista para explicar os novos processos de produção de notícias de uma das áreas mais complexas do jornalismo atual. No entanto, este artigo não pretende denegar a existência de todo um intrincado jogo de relacionamento entre fontes e imprensa, de bastidores e de busca por informações relevantes para a opinião pública, conforme expõe Franklin Martins (2005), em seu livro Jornalismo Político, somente para citar um exemplo. A proposta é adicionar mais um ingrediente - a Internet - nas condições de produção deste mundo por si fascinante que compõe a reportagem política.

\section{Internet e campanhas políticas}

A Internet começou a ser usada timidamente como ferramenta de campanha em 1998, mas seu uso era bastante limitado à formação da imagem institucional do candidato. Até mesmo devido aos recursos tecnológicos da época, os sites eram mais estáticos. Foi, de toda forma, o ano em que os assessores de imprensa voltados para a política começaram a imaginar o quão facilitador seria se as equipes de campanha começassem a produzir seu próprio noticiário e enviassem a cobertura já pronta ás redações, ao invés de mandar agendas enormes, as quais dificilmente a imprensa conseguiria cobrir integralmente.

O tempo passou e a Internet tornou-se cada vez mais amigável para quem queira disponibilizar algum tipo de conteúdo. Hoje, atualizar um website em tempo real é uma tarefa que pode ser feita com facilidade, por meio de interfaces simples e usáveis. Na campanha de 2006, em consequência, a Internet, tornou-se uma ferramenta fundamental para qualquer candidato. É quase inadmissível algum que não tenha site ou e-mail ou, ainda, perfil no Orkut.

Mas e o jornalismo? Poderia-se imaginar que, com toda a facilidade propiciada por esse novo meio de comunicação, a credencial de jornalista poderia se desvalorizar, quando comparada aos veículos tradicionais de mídia: tevê, rádio, jornais e revistas. Em alguns aspectos a Internet vem tornando, de certa forma, o diploma de jornalismo "dis- 
pensável". É o caso, por exemplo, dos produtos das chamadas redes sociais, nos quais o relacionamento entre os interlocutores é pretensamente direto, ou não mediado, como Orkut, YouTube, entre outros. No entanto, com relação ao jornalismo político, o que ocorre é justamente o fenômeno oposto. A Internet abriu um campo profissional, no momento em que candidatos passam a contratar equipes completas, formando uma redação, com editores, repórteres, fotógrafos, cinegrafistas, para produzir seu próprio noticiário online. Noticiário com formato e deadline de notícia, não de campanha.

Este novo jornalismo político, concebido a partir das facilidades tecnológicas atuais, encontra-se em uma área nebulosa. Ao mesmo tempo em que pode ser visto por alguns como simplesmente mais um recurso de campanha eleitoral, também pode ser encarado por outros (principalmente pelos colegas da grande imprensa) como um manancial de apuração fácil de matérias em fontes classificadas como "confiáveis" ou "oficiais".

Os sites oficiais dos candidatos ganham cada vez mais contornos similares aos portais informativos, com pouca diferença para o que é noticiado nos espaços online das grandes empresas de comunicação (como, por exemplo, O Globo, Jornal do Brasil, Folha de S. Paulo/Uol ou Estado de S. Paulo/Terra). A credibilidade de usar este formato, como pode ser observado em campanhas, influencia diretamente na produção das notícias pelos veículos da grande imprensa e modifica, indiretamente, a visibilidade dos candidatos para a sociedade.

Devido ao tempo cada vez mais reduzido que os jornalistas que trabalham em redações possuem para produzir sua cobertura e também graças à eficácia das assessorias de imprensa, que oferecem material farto e correto (em termos factuais, sem adentrarmos por debates ideológicos), o jornalismo político passou a se dividir em dois grandes campos: por um lado, repórteres experientes e colunistas dedicam-se às notícias relevantes, aos grandes temas, com tempo para apurar, pesquisar. Por outro, a ampla agenda diária dos candidatos, do alvorecer até as altas horas, comparada ao exíguo contingente de repórteres que devem dar cobertura, teoricamente, no mínimo aos eventos mais importantes dos candidatos que estejam mais destacados nas pesquisas, faz com que seja humanamente impossível que o trabalho dos jornalistas seja feito sem o apoio das assessorias. O resultado é o aproveita- mento praticamente total do material produzido pelos jornalistas das "redações" das campanhas, já que a confiabilidade técnica dos mesmos seria garantia de que podem ser publicados.

Enfim, o fenômeno cíclico é: os editores de política acompanham as agendas dos candidatos (hoje, principalmente por meio de seus sites ou pelo recebimento de e-mails), selecionam os eventos do dia seguinte que mereçam que uma equipe de jornalistas esteja presente e o restante dos compromissos políticos dos candidatos, na maioria dos casos, serão acompanhados online, por uma nova geração de jornalistas "virtuais", mais acostumados a cobrir eventos confortavelmente sentados em suas cadeiras, na frente das telas dos computadores, do que se deslocando para verificar in loco se o que eles estão apurando é fato.

Políticos, esportistas, figuras públicas de forma geral possuem, principalmente nos dias de hoje, grande exposição na mídia. Devido a esta característica, ressaltam-se por meio delas os papéis sociais que representam no grupo. Ao refletir sobre o fato de candidatos se exporem ao máximo, inclusive na Internet, através de seus sites oficiais, fornecendo todos os seus passos (agenda) e relatos completos do que fizeram (notícias); além de todo um relato de sua vida particular, com algumas passagens que, custa acreditar, tenham alguma relevância para nós (como o candidato ao governo do Estado Sérgio Cabral Filho expondo sua avó e sua mãe, no site e também em seu programa no horário eleitoral gratuito na tevê em 2006), imaginamos que toda essa transparência e exposição são formas de criar uma imagem pública mascarada em vida privada. Sendo assim, nos parece interessante trabalhar com a noção de público e privado apresentada por Richard Sennet, complementando o fenômeno já anteriormente analisado por Jürgen Habermas (1984) em seu estudo sobre as esferas pública e privada.

Sennett (1998, p. 320) afirma que falar do fim da vida pública é falar de uma recusa. "Recusamos ver qualquer valor, qualquer dignidade, na repressão que o mundo vitoriano se impunha conforme a confusão entre o comportamento público e a personalidade se tornava mais aguda. Tentamos ser mais diretos, mais abertos e mais autênticos em nossas relações com os outros. Recusamos que deva haver quaisquer barreiras de comunicação entre as pessoas. Esta idéia determinou a lógica de toda a tecnologia de comunicação do séc. XX.” 
Concordamos com o autor neste ponto, que também encontra similaridades com outras visões filosóficas (como as de Nietzsche ou Bakhtin). A máscara, enquanto princípio de civilidade e preservação do outro, mesmo que seja seu amigo mais próximo, não se traveste mais do caráter público, atualmente, mas sim da exposição da vida privada. O que tentamos defender é que, em pleno séc. XXI, não podemos afirmar que o domínio do público está em declínio. Na verdade, o que está caracterizando este novo milênio é uma nova conformação do público, por meio deste "eu" intimista, sem barreiras, que pode ser encarado também como uma máscara social, trespassada pelo excesso de intimidade. As novas máscaras escondem ao expor tudo ao máximo.

\section{CONCLUSÃO}

É impossível negar que a Internet se torna cada vez mais atraente como veículo de comunicação. E, no caso da política, um veículo sobre o qual as leis eleitorais ainda estão nebulosas. Sendo assim, a tendência é que o mundo da política se aproprie cada vez mais dos espaços deste mundo virtual para projetar a imagem e o discurso planejados em seus bastidores, moldando seus candidatos por meio deste trabalho sutil e ao mesmo tempo direto. Cabe aos jornalistas que trabalham nos editoriais de política a responsabilidade de saber diferenciar a apuração jornalística virtual - hoje em dia uma prática recorrente - da possibilidade de manipulação. Um bom jornalista político recorre às assessorias de imprensa, mas preserva o senso crítico e o hábito de tentar enxergar por trás de belas imagens de campanha.

\section{REFERÊNCIAS}

CASTELLS, M. Internet e sociedade em rede. In: MORAES, D. (Org.). Por uma outra comunicação: mídia, mundialização cultural e poder. 3. ed. Rio de Janeiro: Record, 2005. p. 255-288.

CHAPARro, M. C. Cem anos de assessoria de imprensa no Brasil. In: DUARTE, J. (Org.). Assessoria de imprensa e relacionamento com a mídia: teoria e técnica. 2. ed. São Paulo: Atlas, 2003. p. 81-99.
FERRARI, P. Jornalismo digital. 2. ed. São Paulo: Contexto, 2004.

HABERMAS, J. Mudança estrutural na esfera pública. Rio de Janeiro: Tempo Brasileiro, 1984.

KOPPLIN, E.; FERRARETTO, L. A. Assessoria de imprensa, teoria e prática. 4. ed. Porto Alegre: Sagra-Luzzatto, 2001.

LIMA, G. M. Releasemania: uma contribuição para o estudo do press-release no Brasil. 3. ed. São Paulo: Summus, 1985.

MARTINS, F. Jornalismo político. São Paulo: Contexto, 2005.

SENNETT, R. O declínio do homem público (as tiranias da intimidade). São Paulo: Cia das Letras, 1998.

SODRÉ, M. Antropológica do espelho: uma teoria da comunicação linear e em rede. Petrópolis, RJ: Vozes, 2006. Disponível em: < http://www.observatoriodaimprensa.com.br/ artigos/jd020520011.htm>. Acesso em: 02 maio 2008.

Recebido: 21/05/2008

Received: 05/21/2008

Aprovado: $20 / 06 / 2008$

Approved: 06/20/2008 